\title{
Intégration agriculture-élevage dans un contexte d'accès limité aux intrants de synthèse en milieu tropical de moyenne altitude
}

\author{
Elias Romélio Rasambatra ${ }^{1,2,3 *}$ Patrice Autfray ${ }^{4}$ Eric Vall ${ }^{2}$ \\ Eliel González-Garciá 2 Jean-Michel Mortillaro 5,6 \\ Jean de Neupomuscène Rakotozandriny ${ }^{1}$ Paulo Salgado ${ }^{2}$
}

\begin{abstract}
Mots-clés
Bovin, polyculture élevage, rendement des cultures, agriculture durable, ressource alimentaire pour animaux, typologie, Madagascar
\end{abstract}

\footnotetext{
Submitted: 10 September 2018

Accepted: 20 March 2020

Published: 29 June 2020

DOI: $10.19182 /$ remvt.31876
}

\begin{abstract}
Résumé
Dans le Moyen-Ouest de la région de Vakinankaratra à Madagascar, les exploitations agricoles ont des besoins croissants en fertilisants et en fourrages, et dans le même temps de sérieuses difficultés économiques d'accès aux engrais minéraux et aux aliments de bétail. Cette étude a montré comment l'intégration agriculture-élevage (IAE) a permis de pallier en partie la difficulté d'accès aux intrants agricoles industriels et de contribuer à l'intensification agricole. Des enquêtes auprès de 20 exploitations agricoles ont été menées. A l'aide d'analyses en composantes principales et d'une classification sur la base de treize variables, trois structurelles (superficie cultivée, nombre de bovins, nombre de mains-d'œuvre familiales) et dix fonctionnelles (production de fumure organique, achat de fumure organique, achat de fertilisants minéraux, épandage de fumure organique, rendement en riz pluvial, rendement en maïs, disponibilité de résidus de cultures, valorisation de résidus de cultures, complémentation de I'alimentation des bovins, durée de pâturage), cinq types d'exploitations ont été caractérisés : un type de petites exploitations avec un niveau d'IAE fort, deux types d'exploitations de taille moyenne avec un niveau d'IAE moyen et faible, et deux types de grandes exploitations avec un niveau d'IAE moyen et faible. La complémentation de l'alimentation des bovins, le nombre de bovins et la durée de pâturage ont le mieux discriminé les exploitations. Les besoins alimentaires énergétiques et protéiques des bovins étaient couverts à l'échelle de l'année pour toutes les exploitations. Les exportations d'azote par les cultures étaient compensées par les apports dans les exploitations au plus fort niveau d'IAE. En conclusion, dans ce contexte d'accès très limité aux intrants industriels, les producteurs se sont tournés vers des stratégies d'IAE, d'une part, pour allouer la fumure organique produite sur les cultures exigeantes (riz et maïs) et, d'autre part, pour couvrir les besoins alimentaires des animaux.
\end{abstract}

- Comment citer cet article : Rasambatra E.R., Autfray P., Vall E., González-Garciá E., Mortillaro J.-M. Rakotozandriny J. de N., Salgado P., 2020. Mixed crop-livestock integration in a context of limited access to synthetic inputs in mid-altitude tropical environments. Rev. Elev. Med. Vet. Pays Trop., 73 (2): 49-59, doi : $10.19182 /$ remvt.31876
1. Université d'Antananarivo, ESSA, BP 175, 101 Antananarivo, Madagascar. 2. CIRAD, UMR SELMET, F-34398 Montpellier, France ; SELMET, Univ Montpellier, CIRAD, INRAE, Institut Agro, Montpellier, France.

3. CIRAD, UMR SELMET, Antsirabe, Madagascar.

4. CIRAD, UPR AIDA, F-34398 Montpellier, France ; AIDA, Univ Montpellier, CIRAD, Montpellier, France ; CIRAD, UPR AIDA, Antsirabe, Madagascar

5. ISEM, Univ Montpellier, CIRAD, CNRS, EPHE, IRD, Montpellier, France.

6. FOFIFA DRZVP, Antananarivo, Madagascar.

* Auteur pour la correspondance

Tél. : +261322612151; email : eliasromelio@yahoo.fr

\section{INTRODUCTION}

Les populations rurales de Madagascar vivent principalement de l'agriculture et de l'élevage. Ces deux activités constituent le principal pourvoyeur d'emplois et de revenu au niveau national, en occupant près de $85 \%$ de la population active, et contribuent à environ $26 \%$ du produit intérieur brut malgache (Sourisseau et al., 2014). Pourtant, la production agricole est insuffisante pour couvrir les besoins alimentaires de la population et pour permettre aux producteurs de dégager un revenu satisfaisant (Dabat et Jenn-Treyer, 2010). L'amélioration de la production agricole est difficile dans un contexte d'accès aux terres cultivables 
de plus en plus contraint, ainsi que d'accès très limité à la mécanisation motorisée et aux intrants agricoles industriels (semences améliorées, herbicides et insecticides, engrais minéraux, aliments bétail concentrés, etc. ; Dabat et Jenn-Treyer, 2010 ; Sourisseau et al., 2014).

Pour intensifier la production agricole, les producteurs malgaches des plateaux d'altitude se tournent vers l'utilisation de fumure organique et de biomasses fourragères produites sur les exploitations pour nourrir le bétail et entretenir la fertilité du sol - Tirel (1987) a défini l'intensification de la production agricole comme étant un investissement en intrants, en capital, en travail, par unité de surface ou par animal, ce qui permet d'atteindre une amélioration de la production. Dans la région du Vakinankaratra où a été réalisée cette étude, les producteurs utilisent très peu ou pas d'intrants agricoles de synthèse et intensifient ainsi leurs productions en valorisant des ressources locales, avec dans certains cas l'abandon de la jachère et le recours au travail du sol en culture attelée (Raharison et al., 2016 ; Razafimahatratra et al., 2017). La plupart des paysans semblent privilégier des stratégies basées sur l'intégration agriculture-élevage (IAE) que Landais et Lhoste (1990) ont définie comme étant le recyclage de la biomasse entre les systèmes de culture et les systèmes d'élevage, et l'exploitation de l'énergie animale à l'échelle de l'exploitation agricole. Les modalités de cette intégration entre agriculture et élevage méritent cependant d'être étudiées, notamment par ses effets sur l'intensification de la production agricole et en particulier sur la couverture des besoins alimentaires du bétail. Cette étude visait à comprendre la place, le rôle et les effets de l'IAE dans les exploitations de polyculture-élevage de la sous-région du Moyen-Ouest de Vakinankaratra pour intensifier la production agricole dans un contexte d'accès limités aux intrants agricoles industriels.

\section{MATERIEL ET METHODES}

\section{Zone d'étude}

Létude a été menée dans la sous-région du Moyen-Ouest du Vakinankaratra, dont le contexte agroécologique est proche des autres régions de moyenne altitude de Madagascar. Elle se situe à une altitude autour de 1000 mètres. Le climat est marqué par une longue saison sèche, de mai à octobre, et une pluviométrie moyenne annuelle d'environ 1300 millimètres par an. La température moyenne annuelle est d'environ $25^{\circ} \mathrm{C}$ (données de la station météorologique d'Ivory ; $19^{\circ} 33^{\prime} \mathrm{S}$; $46^{\circ} 25^{\prime} \mathrm{E}$ ). Le paysage est dominé par des collines (tanety), potentiellement propices pour l'agriculture pluviale. Les bas-fonds sont souvent étroits ce qui limite la riziculture irriguée.

\section{Collecte des données}

L'étude a porté sur 20 exploitations agricoles, réparties dans quatre villages. La sélection a été faite sur la base des connaissances acquises précédemment sur la capacité productive des exploitations (Raharison et al., 2016 ; Razafimahatratra et al., 2017) et la diversité des pratiques d'IAE. Afin d'avoir un échantillon d'exploitations le plus diversifié possible, nous avons pris en compte, parmi les critères de sélection, les pratiques d'utilisation de cultures fourragères, d'élevage de porcs, de complémentation de l'alimentation des zébus avec des fanes de légumineuses, et d'entretien des bovins de trait. Les données provenaient d'enquêtes semi-directives (Euréval, 2010). Elles ont été collectées entre avril et juin 2016 et ont porté sur la structure de l'exploitation, les pratiques d'agriculture et d'élevage, les pratiques d'IAE, et le fonctionnement des exploitations agricoles.

\section{Typologie des pratiques des exploitations agricoles}

\section{Caractérisation des exploitations}

Une typologie a été faite pour comprendre la place et le rôle des pratiques d'IAE dans la diversité des exploitations agricoles. Ainsi, treize variables, qui caractérisaient la structure des exploitations, les pratiques agricoles, les pratiques d'élevage et les pratiques d'IAE, ont été sélectionnées. Les variables de structures retenues ont été : la superficie cultivée, le nombre de bovins, et le nombre de mains-d'œuvre familiales. Le nombre de bovins a été exprimé en unité de bovin tropical (UBT) correspondant à un bovin de 250 kilogrammes de poids vif (PV). Le PV des zébus a été estimé à l'aide d'un ruban barymétrique (Touré et al., 2017). L'équation barymétrique correspondante est PV zébu $(\mathrm{kg})=2,82+0,30 \times \mathrm{PT}$ (périmètre thoracique en $\mathrm{cm}$ ) $-3,0610^{-03} \times \mathrm{PT}^{2}+8,8710^{-05} \times \mathrm{PT}^{3}$. La variable main-d'œuvre familiale a été exprimée en actif agricole et a été calculée avec les coefficients de pondération de l'Organisation des Nations unies pour l'alimentation et l'agriculture (FAO) selon l'âge et le sexe de chaque membre de la famille contribuant aux activités agricoles (Kane, 2010).

Sur la production végétale, les variables retenues pour l'analyse typologique ont été : la production de fumure organique ( $\mathrm{kg} \mathrm{N} / \mathrm{UBT} / \mathrm{an})$; l'achat de fumure organique (kg N/ha surface agricole utile [SAU]/ an) ; l'achat de fertilisants minéraux ( $\mathrm{kg} \mathrm{N} / \mathrm{ha} \mathrm{SAU/an);} \mathrm{l'épandage} \mathrm{de}$ fumure organique ( $\mathrm{kg} \mathrm{N} / \mathrm{ha}$ épandu/an) ; le rendement en riz pluvial ( $\mathrm{t}$ brute/ha/an) ; et le rendement en maïs (t brute/ha/an).

Sur la production animale, nous avons retenu les variables suivantes : la disponibilité de la paille de riz et de la fane d'arachide (unités fourragères [UF]/UBT/an); la valorisation de résidus de cultures (\%); la complémentation de l'alimentation des bovins (UF/UBT/an); et la durée de pâturage (min/jour). La complémentation des bovins concernait uniquement les produits et les résidus de cultures de l'exploitation, et les herbes naturelles collectées par le paysan sur les lieux de pâturage. En effet, les paysans du Moyen-Ouest n'ont pas recours à l'achat de fourrage, de résidus ou d'aliments pour le bétail.

La quantité d'azote apportée par la fumure organique a été calculée à partir des données brutes d'enquête, exprimée d'abord en nombre de charrettes puis convertie en unité de mesure standard (kg de matière fraîche). La transformation (en $\mathrm{kg}$ de matière sèche [MS] et en $\mathrm{kg}$ d'azote) a été réalisée à partir des résultats d'analyse de la MS des 24 échantillons par étuvage et des estimations de la teneur en azote par la spectrométrie dans le proche infrarouge (SPIR). Des prélèvements d'échantillons de fumure organique, entre novembre et décembre 2016, ont permis d'obtenir la teneur en azote de la fumure organique produite au niveau de chaque exploitation agricole $(2,1 \pm$ $0,6 \% \mathrm{~N}$ ). Pour les engrais minéraux, la quantité d'engrais utilisée a été calculée à partir des enquêtes et multipliée par la teneur en azote des fertilisants (11\% N pour l'engrais complet et $46 \%$ N pour l'urée).

Le même protocole que celui de la fumure organique a été utilisé pour obtenir la quantité (en $\mathrm{kg}$ MS) de complémentation alimentaire apportée aux zébus (67 échantillons). La quantité d'énergie apportée par la complémentation de l'alimentation des zébus a été calculée en appliquant des valeurs en énergie nette (UF) estimée à partir des résultats de la composition chimique des échantillons. Ainsi, la valeur énergétique utilisée pour les herbes naturelles (notamment Aristida adscensionis, Aristida multicaulis, Chrysopogon serrulatus, Cynodon dactylon, Digitaria sp., Heteropogon contortus, Hyparrhenia rufa, Imperata cylindrica, Leersia hexandra, Phragmites communis, Richardia scabra, Urena lobata) a été de 0,55 UF/ $\mathrm{kg}$ MS, pour les fourrages cultivés (Stylosanthes guianensis et Brachiaria ruziziensis) elle a été de $0,61 \mathrm{UF} / \mathrm{kg} \mathrm{MS}$, et pour la paille de riz de $0,56 \mathrm{UF} / \mathrm{kg} \mathrm{MS}$. Nous nous sommes référés aux données de la bibliographie pour les valeurs énergétiques du tubercule de manioc et de la fane d'arachide qui sont respectivement de $1,1 \mathrm{UF} / \mathrm{kg}$ MS (Jarrige, 1988) et 0,76 UF/ kg MS (Nantoumé et al., 2000).

\section{Typologie des exploitations}

La typologie des exploitations agricoles a été réalisée à partir d'une analyse en composantes principales (ACP) à l'aide du logiciel $\mathrm{R}$ 
(version 3.3.3) sur les treize variables étudiées. Pour sélectionner le nombre d'axes à utiliser dans l'ACP, nous avons appliqué le critère du coude (Tanagra, 2012). Il s'agit d'étudier la courbe de décroissance des valeurs propres pour détecter les coudes ou les cassures. Ainsi, nous avons retenu les trois premiers axes. L'objectif a été d'obtenir le maximum d'inertie conservée avec le minimum de facteurs.

L'intensité de la liaison des variables de la typologie aux axes a été déterminée par le pourcentage de la contribution absolue des variables aux axes (tableau I). Le sens de la liaison a été déterminé par l'étude des signes des coordonnées des variables aux axes. L'intensité et le sens des liaisons ainsi obtenus ont ensuite été confirmés sur les cercles de corrélations (figure 1). Ensuite, pour avoir des classes qui s'interprètent aisément à l'aide de leurs contributions aux axes et pour pouvoir caractériser les types d'exploitations selon leurs contributions aux axes, nous avons procédé à une classification manuelle des individus (exploitations) comportant les étapes suivantes :

- affectation des exploitations aux axes factoriels ; les exploitations qui avaient une contribution absolue (en \%) à l'axe supérieure à la moyenne ont été affectées à cet axe ; les autres, avec une contribution absolue inférieure à la moyenne sur les trois premiers axes, ont été affectées à l'axe où elles contribuaient le plus ;

- séparation des exploitations en fonction de leur signe positif ou négatif sur les axes ; les exploitations affectées à chaque axe ont été séparées en deux groupes selon le signe positif ou négatif de leurs coordonnées sur cet axe ce qui a conduit à créer six types.

La projection des individus et des types sur les plans factoriels a montré que dans le type 6 un individu était très proche du type 3 et de deux individus du type 4 . Le type a été dissous et ses individus ont

\section{Tableau}

Pourcentage de la contribution des variables de la typologie aux axes dans les exploitations agricoles du Moyen-Ouest de Vakinankaratra à Madagascar

\begin{tabular}{|c|c|c|c|}
\hline & $\begin{array}{c}\text { Axe } 1 \\
(34,50 \%)\end{array}$ & $\begin{array}{c}\text { Axe } 2 \\
(18,27 \%)\end{array}$ & $\begin{array}{c}\text { Axe } 3 \\
(13,27 \%)\end{array}$ \\
\hline $\begin{array}{l}\text { Complémentation de l'alimentation } \\
\text { des bovins (UF/UBT/an) }\end{array}$ & 17,95 & 0,71 & 3,13 \\
\hline Nb. de bovins (UBT) & 13,69 & 5,49 & 8,30 \\
\hline Durée de pâturage (min/jour) & 12,71 & 4,23 & 4,89 \\
\hline $\begin{array}{l}\text { Disponibilité de la paille de riz et de } \\
\text { la fane d'arachide (UF/UBT/an) }\end{array}$ & 11,28 & 11,46 & 3,39 \\
\hline $\begin{array}{l}\text { Production de fumure organique } \\
\text { (kg N/UBT/an) }\end{array}$ & 11,23 & 0,05 & 1,90 \\
\hline Superficie cultivée (ha) & 9,56 & 1,01 & 5,13 \\
\hline $\begin{array}{l}\text { Nombre de main-d'œuvre familiale } \\
\text { (actif agricole) }\end{array}$ & 8,97 & 1,09 & 10,43 \\
\hline Valorisation de résidus de cultures (\%) & 4,19 & 17,00 & 3,38 \\
\hline $\begin{array}{l}\text { Epandage de fumure organique } \\
\text { (kg N/ha épandu/an) }\end{array}$ & 3,79 & 28,41 & 1,85 \\
\hline Rendement en maïs ( $\mathrm{t}$ brute/ha/an) & 3,51 & 7,15 & 3,62 \\
\hline $\begin{array}{l}\text { Achat de fertilisants minéraux } \\
\text { (kg N/ha SAU/an) }\end{array}$ & 1,94 & 10,46 & 9,49 \\
\hline $\begin{array}{l}\text { Rendement en riz pluvial } \\
\text { (t brute/ha/an) }\end{array}$ & 1,09 & 1,31 & 35,48 \\
\hline $\begin{array}{l}\text { Achat de fumure organique } \\
\text { (kg N/ha SAU/an) }\end{array}$ & 0,09 & 11,63 & 9,03 \\
\hline
\end{tabular}

Les variables en caractère gras contribuent fortement à la formation des axes factoriels, les variables en caractère italique contribuent moyennement à la formation des axes, les autres variables contribuent peu à la formation des axes. $1 \mathrm{UBT}=1$ bovin de $250 \mathrm{~kg}$; SAU : surface arable utile ; UF : unité fourragère été affectés aux types 3 et 4 . Au final nous sommes parvenus à cinq types d'exploitations.

Enfin, nous avons effectué une analyse de variance (Anova) sur chacune des variables étudiées, complétée par un test de Tukey (HSD) pour analyser les différences entre modalités selon les types d'exploitations. Le tableau I, qui aide à l'interprétation de la figure 1, a également été utilisé dans ce but. Les variables qui contribuaient fortement à la formation d'un axe (d'après le tableau I) devaient être différentes significativement (d'après Anova et test post hoc) chez les types d'exploitation qui se situent de part et d'autre sur cet axe (figure 1).

\section{Niveau d'intégration agriculture-élevage}

Pour estimer le niveau d'IAE des groupes d'exploitations, deux indicateurs, adaptés de Bénagabou et al. (2017), ont été utilisés : a) le rapport entre la quantité d'azote apportée annuellement par la fumure organique produite au niveau de l'exploitation et la surface agricole totale de l'exploitation ( $\mathrm{kg} \mathrm{N} / \mathrm{ha})$; et b) le rapport entre la quantité d'énergie apportée annuellement par la complémentation des bovins produite par l'exploitation (paille de riz, herbes naturelles fauchées et apportées à l'étable, tubercules de manioc, etc.) et la taille du cheptel bovin (UF/UBT). Lorsque la valeur de ces deux indicateurs était supérieure à la moyenne des 20 exploitations, le niveau d'IAE était considéré comme élevé. A l'inverse, lorsque la valeur de ces deux indicateurs était inférieure à la moyenne des 20 exploitations, le niveau d'IAE était considéré comme faible. Lorsqu'une valeur était au-dessus de la moyenne et l'autre en dessous, le niveau d'IAE était considéré comme moyen.

\section{Couverture des besoins alimentaires des zébus}

Les apports et les besoins alimentaires des bovins ont été calculés pour évaluer le taux de couverture des besoins en énergie (en UF) et en protéines (en grammes de matière azotée digestible [MAD]). Pour le calcul des besoins, nous nous sommes référés à l'ouvrage de Rivière (1991), développé spécifiquement pour les ruminants tropicaux, en procédant pour chaque catégorie de bovins à l'addition des besoins élémentaires journaliers d'entretien, de déplacement, de croissance, de lactation et de travail, selon l'équation suivante : besoin total $=$ besoin d'entretien + besoin de déplacement + besoin de croissance + besoin de lactation + besoin de travail. Ainsi, pour l'estimation des besoins journaliers d'énergie, nous avons utilisé les équations suivantes :

Entretien UF $=0,257+1,08210^{-02} \times \mathrm{PV}-1,36410^{-05} \times \mathrm{PV}^{2}$ $+1,23810^{-08} \times \mathrm{PV}^{3}(\mathrm{PV}:$ poids vif en $\mathrm{kg})$

Déplacement UF $=0,026 \times$ distance $(\mathrm{km}) \times \mathrm{PV} / 100$

Croissance UF pour gmq $100 \mathrm{~g} / \mathrm{j}=0,144+3,09110^{-04} \times \mathrm{PV}$ $+2,51210^{-07} \times \mathrm{PV}^{2}+3,11510^{-10} \times \mathrm{PV}^{3}$

Lactation $\mathrm{UF}=0,4 \mathrm{UF} \times$ production de lait $(\mathrm{kg} / \mathrm{j}$ à $4 \%$ matières grasses $[\mathrm{MG}])$

Travail UF $=1,5 \times$ entretien UF si travail faible $; 2 \times$ entretien UF si travail moyen ; $2,5 \times$ entretien UF si travail fort

(PV : poids vif en $\mathrm{kg}$ )

Pour l'estimation des besoins journaliers de protéines, nous avons utilisé les équations suivantes :

Entretien $\mathrm{MAD}=0,6 \times \mathrm{PV}$

Croissance MAD pour gmq $100 \mathrm{~g} / \mathrm{j}=83,761+0,757 \times \mathrm{PV}-2,426$ $10^{-03} \times \mathrm{PV}^{2}+1,41010^{-06} \times \mathrm{PV}^{3}$

Lactation $\mathrm{MAD}=60 \times$ production de lait $(\mathrm{kg} / \mathrm{j}$ à $4 \% \mathrm{MG})$

Travail MAD $=(0,75 \times \mathrm{PV})-$ entretien MAD 

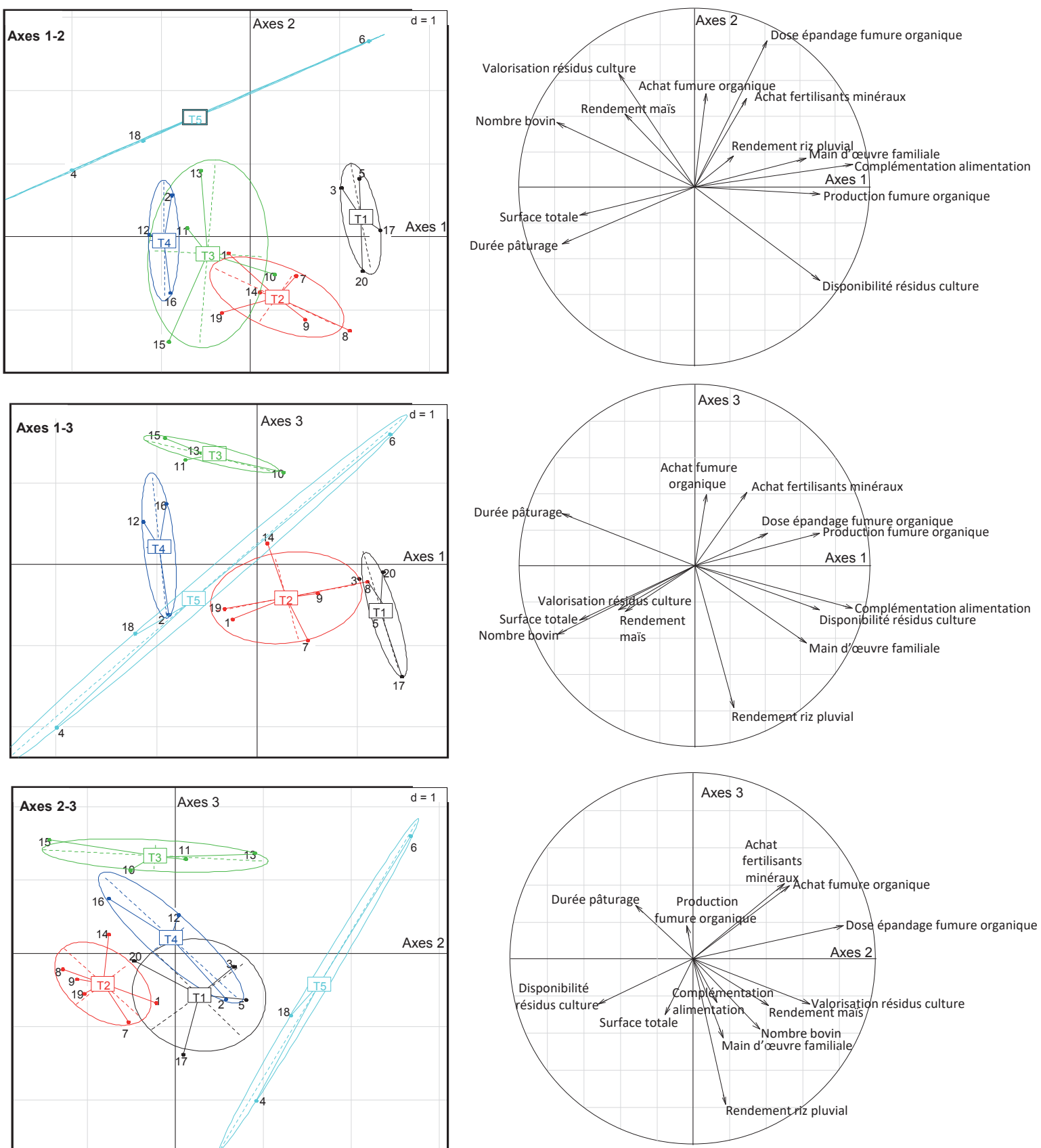

Figure 1 : représentation dans des plans d'analyses en composantes principales des types d'exploitations agricoles $(T)$ du Vakinankaratra à Madagascar et des variables.

Dans la zone d'étude, la distance parcourue par les bovins durant le pâturage a été estimée à un kilomètre en moyenne. Nous avons considéré que les bovins consommaient prioritairement les fourrages et aliments distribués à l'auge avant d'aller au pâturage. Le calcul de la quantité de fourrages et d'aliments ingérés à l'auge a été estimé en prenant en compte les quantités offertes et le taux de refus de chaque catégorie d'aliments, obtenus par suivi et complétés par des enquêtes, pour chaque exploitation agricole. Les valeurs énergétiques des ressources utilisées dans ces calculs de bilan alimentaire ont été les mêmes que celles citées plus haut. Les valeurs protéiques ont été issues des mêmes sources d'informations que les valeurs énergétiques.
Elles ont été de $55,3 \mathrm{~g} \mathrm{MAD} / \mathrm{kg}$ MS pour les herbes naturelles, 74,6 g MAD/kg MS pour Stylosanthes guianensis, 65,5 g MAD/ $\mathrm{kg}$ MS pour Brachiaria ruziziensis, 4,4 g MAD/kg MS pour la paille de riz, et 11,0 g MAD $/ \mathrm{kg}$ MS pour le tubercule de manioc. Le taux de couverture des besoins nutritionnels était égal au rapport : $100 \times$ apports nutritionnels annuels (UF ou g MAD) / besoins alimentaires (UF ou g MAD).

Pour calculer la quantité de MS ingérée au pâturage, nous avons d'abord calculé la consommation théorique ( $c f$. ci-après), puis nous avons retranché la quantité de fourrages et d'aliments ingérés à l'auge, de façon à obtenir une ingestion totale de MS qui ne dépasse pas 
6,25 kg MS/UBT/jour (Guerin et al., 1986). La consommation théorique est ici l'ingestion au pâturage calculée en utilisant la durée quotidienne de pâturage des bovins de chaque exploitation et la capacité maximale d'ingestion d'aliments chez les zébus. Nous avons considéré qu'une journée complète de pâture durait six heures et que les zébus consommaient environ 6,25 kg MS/jour par UBT (Guerin et al., 1986). La disponibilité du fourrage au pâturage étant variable durant l'année, nous avons établi un indice de disponibilité pour chaque mois en nous référant à la quantité de biomasse estimée par Razafinarivo et al. (2017). Cet indice a ensuite été corrigé pour les mois d'août à décembre pour correspondre à la situation de la zone d'étude. L'indice de disponibilité est compris entre 0,23 et 1. Ainsi, la formule d'estimation de la MS volontairement ingérée (MSVI) au pâturage (kg MS/ UBT/jour) utiliséea été : (durée de pâturage [en h] / 6) × 6,25 × indice de disponibilité. De la capacité d'ingestion au pâturage, obtenue par cette formule, a été retranchée la quantité de fourrages et d'aliments ingérés à l'auge pour avoir la quantité de MS ingérée au pâturage.

\section{Couverture des exportations en azote des cultures}

Un bilan apparent a été effectué à l'échelle de l'exploitation de manière à estimer le niveau de couverture des besoins en azote pour les cultures comme un indicateur d'IAE. Un bilan azoté apparent est un bilan où seulement les apports et les exportations d'azote effectués par les paysans au niveau des parcelles cultivées sont pris en compte, sans intégrer la fixation symbiotique d'azote par les légumineuses ni les pertes d'azote pendant et après l'épandage des fertilisants. Les apports d'azote aux cultures correspondent à la quantité d'azote dans la fumure organique et dans les fertilisants minéraux épandus sur les parcelles. La détermination de la teneur en azote des fertilisants a été décrite plus haut.

Les exportations correspondaient : a) aux produits des cultures (grains de céréales et légumineuses, tubercules) qui sont exportés des parcelles pour être autoconsommés et/ou vendus; et b) aux résidus de cultures (paille de riz et fanes d'arachide) transportés au niveau de la ferme pour complémenter l'alimentation des bovins ou pour être utilisés comme litière. Ainsi, les quantités de résidus de cultures qui restaient sur les parcelles n'ont pas été comptabilisées dans le calcul des exportations et nous formulons l'hypothèse que la quantité d'azote exportée par ces résidus retournait au sol lors de la dégradation de ces résidus. La quantité d'azote contenu dans les biomasses exportées des parcelles a été calculée ainsi : exportation $(\mathrm{kg} \mathrm{N})=$ rendement $(\mathrm{kg} \mathrm{MS} / \mathrm{ha}) \times$ surface cultivée $(\mathrm{ha}) \times$ teneur de la biomasse en azote $(\mathrm{kg} \mathrm{N} / \mathrm{t} \mathrm{MS})$.

La concentration en azote du riz a été estimée à partir des résultats de Rakotoson et al. (2017) avec la variété Nerica 4 à 12,6 et 5,7 kg N, respectivement pour une tonne de grain et une tonne de paille (indice de récolte de 0,5 , qui est la proportion du grain par rapport à la biomasse aérienne totale), soit une exportation totale de $18,3 \mathrm{~kg} \mathrm{~N}$ pour une tonne de grain et une tonne de paille. La teneur en azote des grains de maïs a été calculée par rapport aux données d'Herve et al. (2013). Dans nos calculs, nous avons considéré que les concentrations en azote des graines et des fanes d'arachide, des graines de pois de terre et de soja, et des tubercules de manioc étaient respectivement : 45,0; 17,8; 31,7; 75,0 et 4,5 kg N/t MS (Husson et al., 2009 ; Heuzé et al., 2016).

Cette méthode de détermination de la compensation des prélèvements des cultures n'a pas tenu compte des apports supplémentaires par la minéralisation de la matière organique du sol et des pertes d'azote par lessivage et/ou lixiviation. Le taux de couverture des exportations d'azote des parcelles (pour toute la surface cultivée) est égal à 100 $\times$ apports annuels $\mathrm{N}(\mathrm{kg} \mathrm{N})$ / exportations $(\mathrm{kg} \mathrm{N})$.
RESULTATS

\section{Typologie des exploitations en fonction des variables étudiées}

A la suite de l'examen des valeurs propres, nous avons retenu les trois premiers axes pour réaliser l'ACP. La figure 1 présente les exploitations agricoles, les groupes d'exploitations, et les variables dans les plans factoriels formés par les trois premiers axes. L'axe 1 couvre 34,5\% de la variabilité des données, l'axe 2 couvre 18,3\% et l'axe 3 couvre 13,3\%. Ainsi, l'ensemble des trois axes explique $66 \%$ de la variance.

Sur les 13 variables entrant dans l'analyse, la complémentation de l'alimentation des bovins a expliqué le mieux la distribution des données, suivie du nombre de bovins, de la durée de pâturage, de la disponibilité des résidus de cultures (tableau I). En effet, la complémentation de l'alimentation des bovins a contribué le plus à la formation de l'axe 1 (tableau I). Elle a différencié significativement les exploitations à niveau d'IAE forte (T1) des exploitations à niveau d'IAE faible (T3 et T4 ; tableau II) qui se situaient de part et d'autre de l'axe 1 (figure 1). Pour les variables ayant des contributions faibles à la formation des axes (tableau I), l'Anova n'a pas montré de différence significative entre les types d'exploitations (tableau II)

La proximité des vecteurs des variables avec les axes a indiqué que la complémentation de l'alimentation des bovins (UF/UBT) et la production de fumure organique $(\mathrm{kg} \mathrm{N} / \mathrm{UBT})$ sont liées à l'axe 1, dans le sens positif. La surface totale (ha), le nombre de bovins (UBT) et la durée de pâturage (min/jour) sont liés à l'axe 1 dans le sens négatif. Ainsi, plus les exploitations se situent à droite sur les plans 1-2 et 1-3 plus elles augmentent la quantité d'intrants pour l'élevage bovin ainsi que la production de fumure organique. Plus les exploitations se situent à gauche sur les plans 1-2 et 1-3, plus elles ont de grandes surfaces agricoles avec un grand nombre de bovins et plus elles allongent la durée quotidienne de pâturage. La surface totale (ha) et le nombre de bovins (UBT) varient ainsi dans le même sens, ce qui pourrait traduire un maintien de la taille du cheptel bovin en fonction de la surface cultivée.

La valorisation des résidus de cultures, l'achat de fumure organique, la dose d'épandage de fumure organique ainsi que l'achat de fertilisants minéraux sont liés à l'axe 2 dans le sens positif. La disponibilité de résidus de cultures est liée à l'axe 2 dans le sens négatif. Et donc, plus les exploitations se situent en haut sur le plan 1-2 et à droite sur le plan 2-3, plus elles valorisent les résidus de cultures pour l'alimentation des zébus, importent des fertilisants minéraux et organiques dans leur système de production, mettent de grandes quantités de fumure organique par unité de surface, et moins elles disposent de résidus de cultures pour alimenter les zébus.

La disponibilité de la main-d'œuvre familiale et le rendement en riz pluvial sont liés à l'axe 3 dans le sens négatif. Plus les exploitations agricoles se situent en haut sur le plan 1-3 et sur le plan 2-3, moins elles disposent de main-d'œuvre familiale et elles ont de faibles rendements en riz pluvial.

L'analyse de la contribution des individus (les exploitations) à la formation des trois premiers axes de l'ACP a permis de répartir manuellement les exploitations agricoles en cinq types selon leurs caractéristiques liées aux facteurs de production et à leur niveau d'IAE. En suivant la démarche de classification manuelle à partir des contributions aux axes et coordonnées factorielles des individus (exploitations), nous avons identifié cinq types d'exploitations. Le tableau II présente leurs principales caractéristiques.

Les résultats ont montré que les exploitations agricoles de notre échantillon avaient des structures et des systèmes de production contrastés. Le niveau d'IAE a été un critère discriminant. Nous présentons ciaprès les types d'exploitations, des plus petites aux plus grandes, en précisant pour chaque type leur niveau d'IAE. 


\section{Tableau II}

Structure des exploitations agricoles du Moyen-Ouest de Vakinankaratra à Madagascar, niveau d'IAE, pratiques d'alimentation des zébus et pratiques de gestion de la fertilité des sols et rendement des cultures

\begin{tabular}{|c|c|c|c|c|c|c|c|c|}
\hline & $\begin{array}{c}T 1 \\
n=4\end{array}$ & $\begin{array}{c}T 2 \\
n=6\end{array}$ & $\begin{array}{c}T 3 \\
n=4\end{array}$ & $\begin{array}{c}T 4 \\
n=3\end{array}$ & $\begin{array}{c}\text { T5 } \\
\mathrm{n}=3\end{array}$ & Moy & ET & p \\
\hline \multicolumn{9}{|l|}{ Caractéristiques structurelles des exploitations } \\
\hline Superficie cultivée (ha) & $3,5^{\mathrm{a}}$ & $6,0^{\mathrm{a}}$ & $5,8^{\mathrm{a}}$ & $7,0^{\mathrm{a}}$ & $8,0^{\mathrm{a}}$ & 5,9 & 3,2 & $0,491^{N S}$ \\
\hline Nb. de bovins (UBT) & $2,7^{\mathrm{a}}$ & $2,9^{\mathrm{a}}$ & $4,1^{\mathrm{a}, \mathrm{b}}$ & $6,0^{a, b}$ & $10,3^{b}$ & 4,7 & 3,6 & $0,017^{*}$ \\
\hline $\begin{array}{l}\text { Nb. de main-d'œuvre familiale } \\
\text { (actif agricole) }\end{array}$ & $6,1^{\mathrm{a}}$ & $4,3^{a, b}$ & $2,4^{b}$ & $2,3^{b}$ & $3,7^{a, b}$ & 3,9 & 1,8 & $0,012^{*}$ \\
\hline Caractérisation du niveau d'IAE & Forte & Moy & Faible & Faible & Moy & & & \\
\hline $\begin{array}{l}\mathrm{N} \text { apportée par la fumure organique } \\
\text { rapportée à la surface totale (kg N FO/ha) }\end{array}$ & $22,0^{\mathrm{a}}$ & $6,2^{\mathrm{a}}$ & $9,2^{\mathrm{a}}$ & $8,7^{a}$ & $17,4^{\mathrm{a}}$ & 12,0 & 9,6 & $0,079^{N S}$ \\
\hline $\begin{array}{l}\text { Energie apportée par la } \\
\text { complémentation des zébus rapportée } \\
\text { à la taille du cheptel bovin (UF/UBT/an) }\end{array}$ & $918,0^{\mathrm{a}}$ & $733,8^{a, b}$ & $517,5^{b}$ & $519,2^{b}$ & $587,4^{a, b}$ & 673,2 & 197,9 & $0,008^{* *}$ \\
\hline \multicolumn{9}{|l|}{ Pratiques d'alimentation des zébus } \\
\hline $\begin{array}{l}\text { Disponibilité de la paille de riz } \\
\text { et de la fane d'arachide (UF/UBT/an) }\end{array}$ & $1452^{a, b}$ & $1616^{\mathrm{a}}$ & $698^{a, b}$ & $545^{\mathrm{a}, \mathrm{b}}$ & $537^{b}$ & 1077 & 643 & $0,012^{*}$ \\
\hline Valorisation de résidus de cultures (\%) & $39^{a}$ & $30^{\mathrm{a}}$ & $30^{\mathrm{a}}$ & $59^{a}$ & $65^{\mathrm{a}}$ & 41 & 21 & $0,052 \mathrm{NS}$ \\
\hline $\begin{array}{l}\text { Complémentation de l'alimentation } \\
\text { des bovins (UF/UBT/an) }\end{array}$ & $918^{\mathrm{a}}$ & $734^{a, b}$ & $517^{b}$ & $519^{b}$ & $587^{a, b}$ & 673 & 198 & $0,008^{* *}$ \\
\hline Durée de pâturage (min/jour) & $276^{\mathrm{a}}$ & $329^{a, b}$ & $384^{b}$ & $377^{b}$ & $319^{a, b}$ & 335 & 53 & $0,018^{*}$ \\
\hline \multicolumn{9}{|c|}{ Pratiques de gestion de la fertilité des sols et rendement des cultures } \\
\hline $\begin{array}{l}\text { Production de fumure organique } \\
\text { (kg N/UBT/an) }\end{array}$ & $25,3^{\mathrm{a}}$ & $13,9^{\mathrm{a}}$ & $14,4^{\mathrm{a}}$ & $10,0^{\mathrm{a}}$ & $11,1^{\mathrm{a}}$ & 15,3 & 8,5 & $0,107^{N S}$ \\
\hline $\begin{array}{l}\text { Achat de fumure organique } \\
\text { (kg N/ha SAU/an) }\end{array}$ & $1,3^{\mathrm{a}}$ & $1,0^{\mathrm{a}}$ & $3,7^{\mathrm{a}}$ & $0,8^{\mathrm{a}}$ & $3,7^{\mathrm{a}}$ & 2,0 & 2,8 & $0,422 \mathrm{NS}$ \\
\hline $\begin{array}{l}\text { Achat de fertilisants minéraux } \\
\text { (kg N/ha SAU/an) }\end{array}$ & $0,5^{\mathrm{a}}$ & $0,3^{\mathrm{a}}$ & $1,4^{\mathrm{a}}$ & $0,2^{\mathrm{a}}$ & $2,7^{\mathrm{a}}$ & 0,9 & 1,7 & $0,345^{\mathrm{NS}}$ \\
\hline $\begin{array}{l}\text { Epandage de fumure organique } \\
\text { (kg N/ha épandu/an) }\end{array}$ & $46,6^{\mathrm{a}}$ & $19,2^{b}$ & $29,1^{a, b}$ & $26,5^{a, b}$ & $49,3^{\mathrm{a}}$ & 32,2 & 15,6 & $0,007^{* *}$ \\
\hline Rendement en riz pluvial (t brute/ha/an) & $2,0^{\mathrm{a}}$ & $1,8^{\mathrm{a}}$ & $1,1^{\mathrm{a}}$ & $1,4^{\mathrm{a}}$ & $2,0^{\mathrm{a}}$ & 1,7 & 0,5 & $0,060^{N S}$ \\
\hline Rendement en maïs (t brute/ha/an) & $0,9^{\mathrm{a}}$ & $1,0^{\mathrm{a}}$ & $1,2^{\mathrm{a}}$ & $1,5^{\mathrm{a}}$ & $2,1^{\mathrm{a}}$ & 1,3 & 0,8 & $0,372^{\mathrm{NS}}$ \\
\hline
\end{tabular}

IAE : intégration agriculture-élevage ; $1 \mathrm{UBT}=1$ bovin de $250 \mathrm{~kg} ; \mathrm{SAU}$ : surface arable utile ; Moy : moyenne ; ET : écart-type ; a,b Les chiffres sur une même ligne suivis des mêmes lettres ne diffèrent pas au seuil de $5 \%$; NS non significatif $(\mathrm{p} \geq 0,05) ;{ }^{*}$ faiblement significatif $(0,01 \leq \mathrm{p}<0,05) ;{ }^{* *}$ moyennement significatif $(0,001 \leq \mathrm{p}<0,01)$

Les exploitations agricoles de petite taille à niveau d'IAE élevé (type 1 ou T1) étaient caractérisées par un nombre d'UBT de bovins nettement en dessous de la moyenne. Elles disposaient d'une importante quantité de main-d'œuvre familiale. La disponibilité par UBT de résidus de paille de riz et des fanes d'arachide était moyenne. La complémentation alimentaire par UBT était également élevée. Les bovins de ces exploitations restaient plus longtemps dans le parc ou à l'étable. La dose d'épandage de fumure organique était élevée (tableau II).

Les exploitations agricoles de taille moyenne à niveau d'IAE moyenne en faveur de l'élevage (type 2 ou T2) possédaient un faible nombre de bovins. La disponibilité de la main-d'œuvre familiale était moyenne. La disponibilité par UBT de la paille de riz et des fanes d'arachide était élevée. La complémentation alimentaire par UBT était moyenne. La durée de pâturage était moyenne (5 h et $30 \mathrm{~min}$ ). La dose d'épandage de fumure organique était faible (tableau II).

Les exploitations agricoles de taille moyenne à niveau d'IAE faible (type 3 ou T3) avaient un nombre moyen d'UBT de bovins. La disponibilité par UBT de la paille de riz et des fanes d'arachide était moyenne. La complémentation alimentaire par UBT était faible. La durée de pâturage était élevée. La dose d'épandage était moyenne (tableau II).
Les exploitations agricoles de grande taille à niveau d'IAE faible (type 4 ou T4) avaient un nombre moyen d'UBT de bovins. Ces exploitations comportaient peu d'actifs agricoles dans la famille. La paille de riz et les fanes d'arachide étaient moyennement disponibles pour les bovins. La complémentation alimentaire par UBT était faible (tableau II).

Les exploitations agricoles de grande taille à niveau d'IAE moyenne en faveur de l'agriculture (type 5 ou T5) avaient un nombre d'UBT élevé. La disponibilité de la main-d'œuvre familiale était moyenne. La paille de riz et les fanes d'arachide étaient très peu disponibles pour les bovins. La complémentation alimentaire par UBT était moyenne. La durée de pâturage était moyenne. La dose d'épandage de fumure organique était élevée (tableau II).

\section{Couverture des besoins des troupeaux et des exportations d'azote par les cultures}

Dans tous les types d'exploitations agricoles, les besoins énergétiques et protéiques des bovins étaient couverts (bilan > $90 \%$ ) (tableau III). Globalement, la complémentation a contribué à 47,9\% de l'énergie ingérée annuellement (paille de riz : 23,6 \% ; herbes naturelles : 


\section{Tableau III}

Bilan énergétique et protéique de I'alimentation des zébus des exploitations agricoles du Moyen-Ouest de Vakinankaratra à Madagascar

\begin{tabular}{|c|c|c|c|c|c|c|c|c|}
\hline & T1 & $\mathrm{T} 2$ & T3 & $\mathrm{T} 4$ & T5 & Moy & ET & $\mathbf{P}$ \\
\hline \multicolumn{9}{|c|}{ Bilan énergétique et protéique de l'alimentation des zébus et bilan partiel d'azote sur les cultures } \\
\hline Besoins énergétiques (UF/an) & $3213^{a}$ & $3718^{\mathrm{a}}$ & $5433^{a, b}$ & $7039^{a, b}$ & $13350^{\mathrm{b}}$ & 5903 & 4489 & $0,001^{* *}$ \\
\hline Apports énergétiques (UF/an) & $3164^{\mathrm{a}}$ & $3747^{a}$ & $5162^{a, b}$ & $6539^{a, b}$ & $12614^{b}$ & 5670 & 4164 & $0,011^{*}$ \\
\hline Couverture des besoins énergétiques (\%) & 98 & 101 & 96 & 93 & 94 & 96 & 5 & \\
\hline Besoins protéiques (g MAD/an) & $240495^{\mathrm{a}}$ & $278340^{\mathrm{a}}$ & $316692^{a, b}$ & $441967^{a, b}$ & $860736^{b}$ & 390345 & 307989 & $0,048^{*}$ \\
\hline Apports protéiques (g MAD/an) & $211146^{\mathrm{a}}$ & $265480^{\mathrm{a}}$ & $452505^{a, b}$ & $514632^{a, b}$ & $960818^{b}$ & 433692 & 320074 & $0,006^{* *}$ \\
\hline Couverture des besoins protéiques (\%) & 88 & 95 & 143 & 116 & 112 & 111 & 33 & \\
\hline \multicolumn{9}{|c|}{ Bilan entre apports et exportations d'azote sur les cultures } \\
\hline $\begin{array}{l}\text { Apport d'azote par la fumure organique } \\
\text { et les fertilisants minéraux (kg N/an) }\end{array}$ & $73,7^{a, b}$ & $42,3^{\mathrm{a}}$ & $70,7^{a, b}$ & $65,7^{a, b}$ & $91,5^{b}$ & 65,2 & 24,3 & $0,036^{*}$ \\
\hline $\begin{array}{l}\text { Exportations de N par les cultures } \\
\text { (kg N/an) }\end{array}$ & $49,2^{\mathrm{a}}$ & $74,0^{\mathrm{a}}$ & $62,6^{\mathrm{a}}$ & $79,2^{\mathrm{a}}$ & $161,7^{\mathrm{a}}$ & 80,7 & 63,5 & $0.200 \mathrm{NS}$ \\
\hline $\begin{array}{l}\text { Bilan apports fertilisants / exportations } \\
\text { par les cultures }(\%)\end{array}$ & 150 & 57 & 99 & 83 & 57 & 81 & 59,0 & \\
\hline
\end{tabular}

Moy : moyenne ; ET : écart-type ; UF : unité fourragère, MAD : matière azotée digestible ; a,b Les chiffres sur une même ligne suivis des mêmes lettres ne diffèrent pas au seuil de $5 \%$; ${ }^{\mathrm{NS}}$ non significatif $(\mathrm{p} \geq 0,05) ;{ }^{*}$ faiblement significatif $(0,01 \leq \mathrm{p}<0,05) ;{ }^{* *}$ moyennement significatif $(0,001 \leq \mathrm{p}<0,01)$

$18,7 \%$; tubercule de manioc : $3,5 \%$; fourrages cultivés : $1,4 \%$, fane d'arachide : $0,7 \%$ ), contre $52,1 \%$ pour le pâturage. Les exportations d'azote des parcelles par les cultures n'ont pas été compensées par les apports d'azote sur les parcelles pour deux types d'exploitations (T2, T4 et T5 ; tableau III). Elles ont été couvertes (bilan > $90 \%$ ) pour les deux autres types (T1 et T3).

\section{DISCUSSION}

\section{Contribution de l'IAE à la couverture des besoins alimentaires des bovins}

\section{Alimentation des bovins au Moyen-Ouest et ailleurs}

Pour l'ensemble des exploitations agricoles étudiées, les bilans énergétiques (UF) ont atteint un niveau de $90 \%$ et il y a eu un dépassement de près de $10 \%$ des besoins protéiques (MAD). Au Népal, des études montrent que sur l'année les apports alimentaires couvrent $95 \%$ des besoins en énergie nette (UFL) et $106 \%$ des besoins protéiques (MAD) d'un troupeau (Dobremez, 1986). Comme dans notre étude, cet équilibre alimentaire indique qu'en général les animaux ne perdent pas de poids d'une année à l'autre. Cependant, cette situation de couverture des besoins annuels d'énergie et de protéines n'exclut pas l'éventuelle fluctuation interannuelle du taux de couverture autour de l'équilibre. Dans beaucoup de régions tropicales, le pâturage naturel de la saison sèche ne subvient pas aux besoins des bovins. A Madagascar, d'après Rasambainarivo et Ranaivoarivelo (2003), la perte pondérale peut aller jusqu'à $25 \%$ du poids vif en fin de la saison des pluies. Toujours d'après ces auteurs, au cours de la saison des pluies, il y a des gains qui varient entre 41 et $98 \mathrm{~kg}$ de poids vif par tête de bovin.

Des suivis sur des projets d'élevage familiaux réalisés dans la province de Tuy (Ouest du Burkina Faso) de janvier à juin montrent que la couverture des besoins énergétiques (UF/UBT) des bovins de trait est en moyenne $108 \%$; et la couverture des besoins protéiques (MAD/ UBT) est en moyenne $143 \%$ (Delma et al., 2016). Comme dans le cas des exploitations du Moyen-Ouest étudiées, les besoins en énergie et en protéines des bovins sont globalement couverts sur l'année.
Pour des exploitations bovines allaitantes de la Creuse (France), Veysset et al. (2007) trouvent qu'en moyenne sur la durée de la période hivernale la couverture des besoins énergétiques (UFL) des bovins est de $120 \%$. La nutrition azotée, exprimée par les bilans des protéines digestibles dans l'intestin grêle limitées par l'azote (PDIN), est juste équilibrée avec un taux de couverture des besoins de $100 \%$.

L'analyse de corrélation a montré que le taux de couverture des besoins énergétiques a varié en fonction de la complémentation de l'alimentation des bovins, et notamment de l'affouragement avec des herbes naturelles pendant la saison sèche. Les résultats des travaux de Sib et al. (2017) vont dans ce sens. A priori, au Moyen-Ouest de Vakinankaratra, la période critique se situe à la fin de la saison sèche (octobre) quand les animaux sont fortement sollicités pour réaliser des travaux agricoles et quand la disponibilité des herbes naturelles est à son niveau minimal. Vilanova et Smith (2014) rapportent que cette situation se retrouve dans la plupart des pays tropicaux.

\section{Perspectives de recherche-développement et propositions d'amélioration de l'alimentation des bovins}

Les exploitations agricoles pourraient garder les bovins plus longtemps à l'étable ou au parc. Pour soutenir cette pratique, elles auraient besoin d'apporter, autant que possible, des résidus de cultures au niveau de l'étable ou du parc. Pour les exploitations à disponibilité de résidus de cultures réduite (T3), les herbes naturelles pourraient être fauchées pour nourrir les bovins et pour produire de la litière. Ces exploitations pourraient également pratiquer ou valoriser partiellement pour l'alimentation des bovins une partie des fourrages cultivés (Stylosanthes guianensis, Brachiaria ruziziensis, Eleusine coracana, Sorghum bicolor, Vigna unguiculata, entre autres) qui ont été testés et/ou vulgarisés dans la sous-région. Andriarimalala et al. (2013) montrent, dans une localité du lac Alaotra, que ces innovations peuvent potentiellement contribuer à $16 \%$ de la couverture des besoins énergétiques (UFL) et $48 \%$ des besoins protéiques (MAD) des bovins, tout en assurant leur fonction de couverture du sol. Naudin et al. (2015) rapportent qu'un compromis de $40 \%$ à $70 \%$ de la biomasse végétale issue de fourrages cultivés dans des systèmes de semis sous couvert végétal est valorisable pour l'alimentation des bovins. 
La littérature (Rasambainarivo et Ranaivoarivelo, 2003 ; Andriarimalala et al., 2013 ; Raharison et al., 2016) indique qu'en général les bovins malgaches connaissent un déficit alimentaire durant toute la saison sèche (6-7 mois) mais elle n'informe pas sur les composantes (UF, MAD, etc.) en déficit ni sur le niveau de déficit (\%) pendant cette période. Ainsi, pour être opérationnel dans des actions d'amélioration de l'IAE, en complément aux résultats de la présente étude, il importe de réaliser des suivis réguliers des exploitations afin de répartir les besoins et les apports (UF et MAD) du troupeau sur les douze mois de l'année. Cela permettrait de réaliser des bilans alimentaires mensuels, nécessaires pour a) situer dans l'année les moments de déficit alimentaire, b) quantifier le niveau de déficit durant les périodes critiques de l'alimentation des bovins et c) identifier les causes. Dans le but de rechercher et d'expliquer les causes des faiblesses de la mise en œuvre des projets d'élevage familiaux au Burkina Faso, Delma et al. (2016) ont effectué des études comparables à l'analyse susmentionnée de janvier à juin, ce qui a permis de mettre en évidence d'importants déséquilibres alimentaires des bovins (déficits ou excédents) durant ce semestre.

\section{Contribution de l'IAE à la couverture des besoins en fertilisants des cultures}

\section{Bilan de l'azote sur les cultures au Moyen-Ouest et ailleurs}

Cette étude a montré des corrélations entre les pratiques d'alimentation, dont le pâturage et la complémentation, et la production de fumure organique, qui confirment les résultats de Gueydon (1992), et de Coly et al. (2013). Dans notre contexte, la production de fumure organique était faible dans les grandes exploitations et élevée dans les petites exploitations. Coly et al. (2013), au Sénégal, trouvent une tendance contraire, en raison notamment d'une complémentation (par tête de bovin) plus élevée dans les grandes exploitations que dans les petites. En effet, la production de fumure organique par UBT est une illustration des efforts de collecte de la fumure par les exploitations. Elle est liée aux efforts de complémentation des animaux (influençant le temps de présence au parc) et à la quantité de refus des fourrages distribués dans le parc participant à produire la fumure.

Dans cette étude, sur la moyenne des exploitations étudiées, le bilan partiel d'azote a été près de $100 \%$. Rakotoarisoa et al. (2010) trouvent des bilans d'azote compris entre $151 \%$ (systèmes de culture avec labour) et $186 \%$ avec des systèmes biodiversifiés sans travail du sol pour le cas des exploitations d'Andranomanelatra. Alvarez et al. (2014) montrent, dans des cas d'exploitations agricoles d'Antsirabe, que les bilans partiels d'azote (total d'azote apporté dans l'exploitation - total d'azote exporté de l'exploitation) sont positifs (plus de $50 \mathrm{~kg} \mathrm{~N} / \mathrm{ha} / \mathrm{an}$ ) pour tous les types étudiés. Sur la base de cette comparaison, le bilan (partiel) d'azote est bien meilleur dans les exploitations laitières des Hautes Terres que dans les exploitations du Moyen-Ouest du Vakinankaratra. Par ailleurs, la dose d'épandage est près de cinq fois plus élevée dans les exploitations des Hautes Terres $(157 \mathrm{~kg} \mathrm{~N} / \mathrm{ha}$ vs $32 \mathrm{~kg} \mathrm{~N} / \mathrm{ha}$ dans le MoyenOuest). Une prise en compte de la fixation symbiotique de l'azote par les légumineuses aurait pu changer les résultats des deux côtés car elles occupent près de $23 \%$ de la superficie cultivée et semblent par conséquent avoir une importance particulière au niveau des exploitations du Moyen-Ouest du Vakinankaratra (Razafimahatratra et al., 2017). Des études menées au Brésil par Scopel et al. (2005) montrent que le bilan de l'azote sur le cycle du riz pluvial est de $60 \%$ en système de culture conventionnel et de $116 \%$ dans des systèmes biodiversifiés sans travail du sol. Des cas d'étude au Pays-Bas révèlent un bilan d'azote de $244 \%$ dans des exploitations de polyculture-élevage (Schröder et al., 2003).

Puisque les apports en fertilisants minéraux sont extrêmement faibles (8\% des apports d'azote sur les parcelles), les productions végétales dépendent de la production de fumure organique, elle-même liée à l'élevage. Raharison et al. (2017) et Razafimahatratra et al. (2017) sont parvenus à la même conclusion. Ils rapportent, dans la même sous-région, que les fertilisants minéraux sont épandus à la dose de $18 \mathrm{~kg} / \mathrm{ha}$ de surface cultivée totale par an contre $2 \mathrm{t} / \mathrm{ha} /$ an pour la fumure organique.

Dans notre étude le déficit d'apport d'azote a été estimé à 14,0-42,5\%, dans les exploitations T2, T4 et T5. Raharison et al. (2016) rapportent que la disponibilité de fumure organique au Moyen-Ouest ne dépasse pas $1,5 \mathrm{t} /$ ha alors que la recommandation standard d'épandage est de $5 \mathrm{t} /$ ha. Ainsi, le déficit de fumure organique est plus important, de $70 \%$ par rapport à la quantité recommandée. Des déficits d'apport d'azote, par rapport aux besoins des cultures de $80 \%$ et plus (Husson et al., 2009), ont été trouvés par Andriarimalala et al. (2013) dans la région du lac Alaotra. Fanjaniaina et al. (2015) indiquent, sur les Hautes Terres, que les exportations d'azote par les grains et la paille de riz (pour un niveau de rendement de 2,2 t/ha) doivent être compensées par un épandage de fumure organique de 5 à 6 t/ha, à teneur moyenne de $0,9 \%$ d'azote, ce qui est difficilement réalisable pour les exploitations de cette zone, en raison de la disponibilité limitée en paille de riz.

Dans cette première étude de l'IAE au Moyen-Ouest, les pertes d'azotes à l'issue de la minéralisation des matières organiques du sol n'ont pas été prises en compte dans le calcul des bilans. Des auteurs qui les ont prises en compte trouvent des bilans partiels d'azote plus faibles. Ainsi, en fonction du type de sol, les exploitations agropastorales de la province du Tuy (ouest du Burkina Faso) ont des taux de couverture des besoins du sol en fumure organique compris entre $6 \%$ et $32 \%$ selon Blanchard et al. (2014), et entre $9 \%$ et $56 \%$ selon Bénagabou et al. (2017). L'intensification par l'IAE s'observe notamment dans les petites exploitations agricoles (T1) qui appliquent une dose d'épandage de fumure organique élevée et enregistrent un bilan azoté élevé. Pour les autres types d'exploitations (notamment T2 et T4), les résultats de cette étude n'ont pas montré de relation évidente entre le niveau d'IAE et l'intensification de la production agricole.

\section{Perspectives de recherche-développement et propositions d'amélioration de la fumure organique}

Les bilans azotés sont couramment utilisés comme indicateurs de l'état des pertes d'azote du sol et du niveau de restitution de la fertilité par les apports (Alvarez, 2012). Cette étude a donné une première idée du bilan d'azote sur les parcelles des paysans. Nous nous sommes limités à la réalisation d'un bilan partiel d'azote correspondant à la différence entre les entrées d'azote (par les épandages de fumure organique et de fertilisants minéraux) et les sorties d'azote (par les produits et les résidus de cultures collectés) au niveau des parcelles de culture. Un bilan complet de l'azote et d' autres éléments fertilisants, comptabilisant en plus l'ensemble des entrées d'azote par la déposition des déjections durant le pâturage, la sédimentation, la fixation symbiotique, et des sorties d'azote par la minéralisation des matières organiques du sol, les émissions gazeuses, l'érosion et la lixiviation, compléteraient les résultats de cette étude.

Les perspectives d'amélioration de l'alimentation des bovins auraient de grands impacts sur la production de fumure organique. Avec la même taille de cheptel bovin, les exploitations pourraient augmenter la production de fumure organique par des apports plus importants de biomasses végétales (par exemple résidus de cultures, herbes naturelles) au niveau du parc et de l'étable. Pour produire durablement sur les parcelles, ces efforts d'amélioration de la production de fumure organique devraient être entrepris prioritairement par les exploitations agricoles qui sont en bilan négatif d'azote sur les cultures (T2, T4 et T5).

\section{Contribution de l'IAE à l'intensification agricole}

Dans notre étude, les petites exploitations agricoles ont mobilisé le plus l'IAE pour intensifier leurs productions agricoles, dont l'élevage. En effet, les résultats ont montré que dans ce type d'exploitation (T1) la production de fumure organique par UBT, la complémentation de 
l'alimentation par UBT ainsi que le niveau de couverture des besoins énergétiques étaient supérieurs à la moyenne.

Les résultats de Vall et al. (2017) montrent que, dans les zones de savanes d'Afrique subsaharienne, chez les agriculteurs cultivant de petites surfaces ou des surfaces moyennes, l'IAE permet une intensification agricole et un soutien alimentaire à l'élevage. Alvarez et al. (2014) rapportent que dans le contexte des Hautes Terres de Madagascar, l'intensification par, d'une part, une utilisation importante de complément alimentaire sous forme de concentré aux vaches laitières et, d'autre part, une amélioration de la gestion de la fumure organique est plus avantageuse pour les exploitations de polyculture-élevage.

Au Moyen-Ouest, comme dans beaucoup de régions de Madagascar, en raison notamment du faible accès à la motorisation, la plupart des exploitations agricoles gardent au moins deux bovins de trait dans le troupeau pour réaliser le travail du sol ainsi que le transport des intrants et des produits agricoles (Raharison et al., 2017 ; Razafimahatratra et al., 2017). Ainsi, le cheptel bovin des exploitations T1 et $\mathrm{T} 2$, qui était inférieur à trois UBT, était presque exclusivement composé de bovins de trait.

Les exploitations de taille moyenne qui ont un niveau d'IAE faible (T3) ont obtenu un taux de couverture des besoins énergétiques moyen et des besoins protéiques élevés, s'expliquant, non pas par leur effort d'IAE, mais par la durée de pâturage élevée (environ une heure de plus que la moyenne). Pour les T2, T4 et T5, les résultats n'ont pas montré de lien évident entre le niveau d'IAE et l'intensification de l'élevage.

\section{Perspectives de recherche-développement et propositions d'amélioration de l'IAE}

Cette étude a montré qu'en moyenne près de $60 \%$ de la paille de riz et des fanes d'arachide, ainsi que la totalité des résidus de maïs étaient laissés sur les parcelles. Il y aurait ainsi une forte proportion de résidus de cultures qui pourrait être utilisée pour l'alimentation des bovins, et par la même occasion pour l'amélioration de la production de fumure organique. Cependant, la collecte de ces résidus de cultures pour l'affouragement à l'auge des animaux aurait des conséquences fortes sur le disponible fourrager au pâturage, notamment en saison sèche, et impliquerait en parallèle des efforts d'amélioration de la production fourragère. Les exploitations agricoles du Moyen-Ouest de Vakinankaratra ont une potentialité élevée d'intensification par le renforcement de l'IAE. Les conclusions de Razafimahatratra et al. (2017) vont dans ce sens. La diversification de la production agricole, dont l'adoption des cultures fourragères ou des systèmes vivriers fourragers, est également un levier d'intensification par le renforcement de l'IAE, dans la mesure où elle fournit de la biomasse de bonne qualité pour l'alimentation des bovins (Raharison et al., 2017 ; Razafimahatratra et al., 2017). En favorisant le recyclage et la complémentarité entre les différents ateliers de production, les efforts d'IAE dans le Moyen-Ouest pourraient ainsi contribuer à améliorer l'efficience (de l'azote, de l'énergie) des exploitations agricoles et l'autosuffisance alimentaire des ménages, comme le montrent plusieurs auteurs dans différentes situations (Rufino et al., 2006 ; Alvarez et al., 2014 ; Bénagabou et al., 2017).

Nos premiers résultats indiquent l'existence d'interactions entre les exploitations dans les relations agriculture-élevage, qui restent limitées et peu organisées. Ainsi, les résidus de cultures des parcelles d'une exploitation sont également consommés par les zébus des autres exploitations durant le pâturage. Le mouvement de troupeau durant le pâturage entraîne également un transfert de fertilité d'une exploitation à une autre à travers les dépôts de déjections. Le recours à l'achat de fumure organique, pratiqué par $23 \%$ des exploitations (Raharison et al., 2017), favoriserait également une IAE à l'échelle du village ou d'un territoire. La vente de service de traction animale (travail du sol, transport, entre autres) va également dans ce sens. Une approche territoriale permettrait de compléter notre diagnostic concernant les pratiques d'IAE et de prendre en compte les relations et les échanges potentiels de biomasse entre les exploitations (Moraine et al., 2014).

\section{CONCLUSION}

Dans un contexte d'accès limité aux intrants de synthèse, les producteurs se tournent vers différentes stratégies d'IAE comme le maintien de la taille du cheptel bovin en fonction de la surface cultivée (puisque ces deux variables varient dans le même sens), le recyclage des produits et des résidus agricoles pour l'alimentation animale, l'augmentation de la durée de parcage et de la production de fumure organique par UBT. Ces stratégies permettent de disposer de l'énergie animale nécessaire aux travaux des champs et au transport des résidus de récoltes, d'allouer de la fumure organique produite sur les cultures exigeantes et de couvrir les besoins alimentaires des animaux.

Cependant, bien que les besoins énergétiques et protéiques des bovins soient couverts à l'échelle de l'année, il y a un déficit en fumure organique pour soutenir l'intensification de la production agricole dans le domaine pluvial et la fertilisation de cultures exigeantes comme le riz et le maïs. Différentes options sont envisageables, dont un effort de recyclage des résidus de récolte, et un affouragement supplémentaire avec des produits de qualité comme avec les cultures de Stylosanthes guianensis et de Brachiaria ruziziensis promues par des projets. Ces efforts d'IAE, permettraient non seulement de résoudre la contrainte de disponibilité de fumure organique mais également la contrainte de diminution des ressources alimentaires naturelles pour les bovins. Dans la plupart des cas, nous émettons l'hypothèse qu'un renforcement de l'IAE pourrait contribuer à l'amélioration de la couverture des besoins en ressources productives des exploitations et surtout de mieux équilibrer le bilan entre apports et exportations d'azote sur les cultures qui restait déficitaire pour la majorité des situations étudiées.

\section{Remerciements}

Cette étude a reçu le soutien financier du projet System approach for the TRAnsition to bio-DIVersified agroecosystems (STRADIV). Les auteurs remercient les producteurs du Moyen-Ouest pour leur collaboration tout au long de l'étude.

\section{Déclaration des contributions des auteurs}

$\mathrm{PA}, \mathrm{EV}$ et PS ont contribué à la conception et à la planification de l'étude ; ERR a recueilli les données et rédigé la première version du manuscrit ; EGG et JNR ont participé à la planification de l'étude ; JMM et ERR ont effectué les analyses statistiques ; PA, EV, JMM, PS et ERR ont contribué à l'analyse des données et à l'interprétation des résultats ; tous les auteurs autorisent la soumission de la version finale en vue de sa publication.

\section{Conflits d'intérêts}

L'étude a été réalisée sans aucun conflit d'intérêts.

\section{REFERENCES}

Alvarez S., 2012. Pratiques de gestion de la biomasse au sein des exploitations familiales d'agriculture-élevage des hauts plateaux de Madagascar : conséquences sur la durabilité des systèmes. Thèse Doct., Montpellier SupAgro, Montpellier, France, 266 p.

Alvarez S., Rufino M.C., Vayssières J., Salgado P., Tittonell P., Tillard E., Bocquier F., 2014. Whole-farm nitrogen cycling and intensification of crop-livestock systems in the highlands of Madagascar: An application of network analysis. Agric. Syst., 126: 25-37, doi: 10.1016/j. agsy.2013.03.005 
Andriarimalala J.H., Rakotozandriny J.N., Andriamandroso A.L.H., Penot E., Naudin K., Dugué P., Tillard E., et al., 2013. Creating synergies between conservation agriculture and cattle production in crop-livestock farms: a study case in the Lake Alaotra region of Madagascar. Exp. Agr., 49 (3): 352-365, doi: 10.1017/S0014479713000112

Bénagabou O.I., Blanchard M., Bougouma Yaméogo V.M.C., Vayssières J., Vigne M., Vall E., Lecomte P., et al., 2017. Does crop-livestock integration improve energy-use efficiency, recycling and self-sufficiency of smallholder farming systems in Burkina Faso? Rev. Elev. Med. Vet. Pays Trop., 70 (2) 31-41, doi: 10.19182/remvt.31479

Blanchard M., Coulibaly K., Bognini S., Dugué P., Vall E., 2014. Diversité de la qualité des engrais organiques produits par les paysans d'Afrique de I'Ouest: quelles conséquences sur les recommandations de fumure? Biotechnol. Agron. Soc. Environ., 18 (4) : 512-523

Coly I., Diop B., Akpo L. E., 2013. Transformation locale des résidus de récolte en fumier de ferme dans le terroir de la Néma au Saloum (Sénégal). J. Appl. Biosci., 70 (1) : 5640-5651, doi : 10.4314/jab.v70i1.98806

Dabat M.H., Jenn-Treyer O., 2010. Des trappes de pauvreté au développement durable de l'agriculture malgache. In : Madagascar face au défi des objectifs du millénaire pour le développement (Eds. Gastineau B., Gubert F., Robilliard A.S). IRD, Montpellier, France, 299-318, doi : 10.4000/ books.irdeditions.1907

Delma B.J., Bougouma-Yameogo V., Nacro H.B., Vall E., 2016. Fragilité des projets d'élevage familiaux dans les exploitations de polyculture-élevage au Burkina Faso. Cah. Agric., 25 (3) : 35005, doi: 10.1051/cagri/2016019

Dobremez J.F., 1986. Les collines du Népal central ; écosystèmes, structures sociales et systèmes agraires. Tome II : milieux et activités dans un village népalais. Quae, Paris, France, 190 p.

Euréval, 2010. Réaliser un entretien semi-directif. Fiche technique. https://eureval.files.wordpress.com/2014/12/ft_entretien.pdf (consulté 21 juin 2018)

Fanjaniaina M.L., Ramahandry F., Larvy D.J., Razafimanantsoa M.-P., Salgado P., Tillard E., Rabeharisoa L., et al., 2015. Transfert de fertilité et durabilité des systèmes de production : application à la culture du riz. Bull. Acad. Malgache, $\mathrm{XCV} / 1$

Guerin H., Sall C., Friot D., Ahokpe B., Ndoye A., 1986. Ebauche d'une méthodologie de diagnostic de l'alimentation des ruminants domestiques dans un système agropastoral : I'exemple de Thyssé-Kaymor-Sonkorong au Sénégal. Cah. Rech. Dév. (9-10) : 60-69

Gueydon C, 1992. Variations de la valeur fertilisante des fumiers et lisiers de bovins. Influence de la complémentation, du niveau de production et du type de déjections animales. Fourrages, 129 : 59-71

Herve M., Rosengarten P., Bouviala M., 2013. Teneurs en N des organes végétaux récoltés. Méthode d'établissement et valeurs de référence. Comifer France, $27 \mathrm{p}$.

Heuzé V., Tran G., Lebas F., 2016. Graines voandzou (Vigna subterranea). Feedipedia, INRA, CIRAD, AFZ, FAO, www.feedipedia.org/node/530 (consulté 21 mai 2018)

Husson O., Charpentier H., Naudin K., Razanamparany C., Moussa N., Michellon R., Andrianasolo H., et al., 2013. Le choix des itinéraires techniques. In : Manuel pratique du semis direct sur couverture végétale permanente (SCV), Application à Madagascar. CIRAD/GSDM, Montpellier, France, $76 \mathrm{p}$.

Jarrige R., 1988. Alimentation des bovins, ovins et caprins. INRA, Paris, $476 \mathrm{p}$.

Kane G. Q., 2010. Analyse des performances productives des exploitations familiales agricoles de la localité de Zoetelé. Mém. DEA, Université de Yaoundé II, Cameroun, 119 p.

Landais E., Lhoste P. 1990. L'association agriculture-élevage en Afrique intertropicale : un mythe techniciste confronté aux réalités de terrain. Cah. Sci. Hum., 26 (1-2) : 217-235

Moraine M., Duru M., Nicholas P., Leterme P., Therond O., 2014. Farming system design for innovative crop-livestock integration in Europe. Animal, 8 (8): 1204-1217, doi: 10.1017/S1751731114001189

Nantoumé H., Kouriba A., Togola D., Ouologuem B., 2000. Evaluation of the feeding value of forages and byproducts used for feeding small ruminants. Rev. Elev. Med. Vet. Pays Trop., 53 (3): 279-284, doi: 10.19182/remvt.9725

Naudin K., Bruelle G., Salgado P., Penot E., Scopel E., Lubbers M., de Ridder N., et al., 2015. Trade-offs around the use of biomass for livestock feed and soil cover in dairy farms in the Alaotra lake region of Madagascar. Agric. Syst., 134: 36-47, doi: 10.1016/j.agsy.2014.03.003
Raharison T.S., Rasolomanjaka J., Razaka M., Rakotondramanana, 2016. Capitalisation de I'Agro-écologie à Madagascar. GSDM, Madagascar, $111 \mathrm{p}$.

Raharison T., Salgado P., Bélière J.-F., Autfray P., Razafimahatratra M., Rakotofiringa H., 2017. Agro-biodiversité dans les exploitations agricoles familiales du Moyen Ouest de Vakinankaratra : des paysans en avance sur la recherche et le développement agricole durable? In : Forum Recherche Biodiversité et Développement Durable, Fianarantsoa, Madagascar, 30 nov. 2017, 14 p.

Rakotoarisoa J., Oliver R., Dusserre J., Muller B., 2010. Bilan de I'azote minéral au cours du cycle du riz pluvial sous-systèmes de culture en semis direct sous couverture végétale en sol ferralitique argileux à Madagascar. Etude Gestion Sols, 17 (2) : 169-186

Rakotoson T., Dusserre J., Letourmy P., Ramonta I.R., Cao T.-V., Ramanantsoanirina A., Roumet P., et al., 2017. Genetic variability of nitrogen use efficiency in rainfed upland rice. Field Crops Res., 213: 194-203, doi: 10.1016/j.fcr.2017.07.023

Rasambainarivo J.H., Ranaivoarivelo N., 2003. Profil fourrager. Madagascar. Rome, Italie, FAO

Razafimahatratra M., Raharison T., Bélière J.-F., Autfray P., Salgado P., Rakotofiringa H., 2017. Systèmes de production, pratiques, performances et moyens d'existence des exploitations agricoles du Moyen-Ouest du Vakinankaratra. CIRAD, FOFIFA, GSDM, 100 p.

Razafinarivo T.D., Rahetlah V.B., Rakotozandriny J.N., Salgado P., Degenne P., 2017. Développement d'un outil cartographique pour la gestion des ressources pastorales par une approche combinée de télédétection et de modélisation. Livest. Res. Rural Dev., 29 (11)

Rivière R., 1991. Manuel d'alimentation des ruminants domestiques en milieu tropical. IEMVT. La documentation française, Paris, France, 529 p. (Coll. Manuel et précis d'élevage)

Rufino M.C., Rowe E.C., Delve R.J., Giller K.E., 2006. Nitrogen cycling efficiencies through resource-poor African crop-livestock systems. Agric. Ecosyst. Environ., 112 (4): 261-282, doi: 10.1016/j.agee.2005.08.028

Schröder J.J., Aarts H.F.M., Ten Berge H.F.M., Van Keulen H., Neeteson J.J., 2003. An evaluation of whole-farm nitrogen balances and related indices for efficient nitrogen use. Europ. J. Agron., 20 (1-2): 33-44, doi: 10.1016/ S1161-0301(03)00070-4

Scopel E., Douzet J.M., da Silva F.A.M., Cardoso A., Moreira J.A.A., Findeling A., Bernoux M., 2005. Impacts des systèmes de culture en semis direct avec couverture végétale sur la dynamique de l'eau, de l'azote minéral et du carbone du sol dans les Cerrados brésiliens. Cah. Agric., 14 (1) : 71-75

Sib O., Bougouma-Yameogo V.M.C., Blanchard M., Gonzalez-Garcia E., Vall E., 2017. Dairy production in Western Burkina Faso in a context of emergence of dairies: Diversity of breeding practices and proposals for improvement. Rev. Elev. Med. Vet. Pays Trop., 70 (3): 81-91, doi: 10.19182/ remvt.31521

Sourisseau J.-M., Rasolofo P., Bélières J.-F., Guengant J.-P., Ramanitriniony H.K., Bourgeois R., Razafimiarantsoa T.T., et al., 2014. Diagnostic territorial de la région du Vakinankaratra à Madagascar. AFD, Paris, France, 157 p.

Tanagra, 2012. ACP avec R - Détection du nombre d'axes. http://eric.univ-lyon2.fr/\%7Ericco/tanagra/fichiers/fr_Tanagra_Nb_Components_PCA.pdf (consulté 16 fév. 2018)

Tirel J.C. 1987. Valeur et limites des notions d'intensification dans l'analyse de l'évolution des systèmes de production. C.R. Acad. Agric. Fr., 73 (8) : 83-95

Touré A., Antoine-Moussiaux N., Kouriba A., Leroy P., Moula N., 2017. Zootechnical characterization and barymetric formula of the Azawak zebu breed in Menaka, Northern Mali. Rev. Elev. Med. Vet. Pays Trop., 70 (4): 115-120, doi: 10.19182/remvt.31528

Vall E., Marre-Cast L., Kamgang H.J., 2017. Chemins d'intensification et durabilité des exploitations de polyculture-élevage en Afrique subsaharienne : contribution de l'association agriculture-élevage. Cah. Agric., 26 (2) : 25006, doi: 10.1051/cagri/2017011

Veysset P., Agabriel J., Ingrand S., Bébin D., Constant I., Lherm M., Dauphin L., 2007. La conduite de l'alimentation en élevage bovin allaitant: analyse des écarts entre pratiques et recommandations. In : Proc. 14th Renc. Rech. Rumin., Paris, France, 229-232

Vilanova I.X.M., Smith A.J., 2014. Comportement, conduite et bien-être animal. Quae, Montpellier, France, 187 p. 


\section{Summary}

Rasambatra E.R., Autfray P., Vall E., González-Garciá E., Mortillaro J.-M., Rakotozandriny J. de N., Salgado P. Mixed crop-livestock integration in a context of limited access to synthetic inputs in mid-altitude tropical environments

In the Middle West, in the Vakinankaratra region of Madagascar, farms have an increasing need for fertilizers and fodder, and at the same time severe economic constraints to access mineral fertilizers and animal feed. This study shows how crop-livestock integration (CLI) has helped to alleviate part of the difficulty of access to industrial agricultural inputs and contributed to farming intensification. Surveys were conducted with 20 farms. Using principal component analyses and a classification based on thirteen variables, three structural (cultivated surface area, number of cattle, number of family labor) and ten functional (production of organic manure, purchase of organic manure, purchase of mineral fertilizers, application of organic manure, rainfed rice yield, maize yield, availability of crop residues, use of crop residues, cattle supplementation, grazing duration), five types of farms were characterized: one type of small farms with a high level of CLI, two types of medium-sized farms with a medium and low level of CLI, and two types of large farms with a medium and low level of CLI. Cattle supplementation, number of cattle, and grazing duration best differentiated the farms. The energy and protein feed requirements of cattle were covered on a yearly basis for all farms. Nitrogen exports by crops were compensated by inputs on farms with the highest level of CLI. In conclusion, in this context of very limited access to industrial inputs, producers turned to CLI strategies, on the one hand, to allocate the organic manure produced on demanding crops (rice and maize) and, on the other hand, to cover cattle feed requirements.

Keywords: cattle, mixed farming, crop yield, sustainable agriculture, feed resources, typology, Madagascar

\section{Resumen}

Rasambatra E.R., Autfray P., Vall E., González-Garciá E., Mortillaro J.-M., Rakotozandriny J. de N., Salgado P. Integración agricultura-cría en un contexto de acceso limitado a los insumos de síntesis en medio tropical de mediana altitud

En el oeste medio, situado en la región de Vakinankaratra en Madagascar, las explotaciones agrícolas tienen necesidades crecientes de fertilizantes y forrajes, y al mismo tiempo dificultades económicas serias de acceso a los fertilizantes minerales y a los alimentos para el ganado. Este estudio mostró como la integración agricultura-cría (IAC) permitió de paliar en parte la dificultad de acceso a los insumos agrícolas industriales y de contribuir a la intensificación agrícola. Se Ilevaron a cabo encuestas en 20 explotaciones agrícolas. Con la ayuda de análisis de componentes principales y una clasificación en base a trece variables, tres estructurales (superficie cultivada, número de bovinos, cantidad de mano de obra familiar) y diez funcionales (producción de estiércol orgánico, compra de estiércol orgánico, compra de fertilizantes minerales, esparcimiento de estiércol orgánico, rendimiento de arroz pluvial, rendimiento de maíz, disponibilidad de residuos de cultivos, valorización de los residuos de cultivo, complemento de la alimentación de los bovinos, duración del pastoreo), cinco tipos de explotaciones fueron caracterizadas: un tipo de pequeñas explotaciones con un nivel de IAC fuerte, dos tipos de explotaciones de tamaño mediano con un nivel de IAC medio y bajo, y dos tipos de grandes explotaciones con un nivel de IAC medio y bajo. El complemento alimenticio de los bovinos, el número de bovinos y la duración de pastoreo distinguieron mejor las explotaciones. Las necesidades alimenticias energéticas y proteicas de los bovinos fueron cubiertas a lo largo del año en todas las explotaciones. Las exportaciones de nitrógeno por los cultivos fueron compensadas por los aportes en las explotaciones con un alto nivel de IAC. En conclusión, en este contexto de acceso muy limitado a los insumos industriales, los productores se orientaron hacia estrategias de IAC, por un lado, para destinar el estiércol orgánico producido a los cultivos exigentes (arroz y maíz) y, por otro lado, para cubrir las necesidades alimenticias de los animales.

Palabras clave: ganado bovino, explotación agrícola combinada, rendimiento de cultivos, agricultura sostenible, recursos de piensos, tipología, Madagascar 
